\title{
Electron-density studies on hydrogen bonding in chromone derivatives. Part II: comparative study
}

\author{
Magdalena Małecka • Lilianna Chęcińska • \\ Carsten Paulmann
}

Received: 3 August 2011/Accepted: 30 November 2011/Published online: 17 December 2011

(C) Springer Science+Business Media, LLC 2011

\begin{abstract}
The experimental electron density of a chromone derivative was determined from a multipole refinement of $100 \mathrm{~K} \mathrm{X}$-ray synchrotron data and complemented by theoretical calculations with experimental and optimized geometry. Atomic and topological properties were obtained using the Quantum Theory of Atoms in Molecules approach. The examination of topological parameters unambiguously showed $\pi$-delocalization within the $\mathrm{H}$-bonded ring. The application of source function analysis confirmed the intramolecular $\mathrm{N}-\mathrm{H} \cdots \mathrm{O}$ hydrogen bond to be a resonance-assisted hydrogen bond. The topological study confirmed the covalent nature of $\mathrm{N}-\mathrm{H} \cdots \mathrm{O}$ interaction and the electrostatic nature of weak $\mathrm{C}-\mathrm{H} \cdots \mathrm{O}$ interactions.
\end{abstract}

Keywords Electron density · Hydrogen bonding · Chromones $\cdot$ Source function $\cdot$ RAHB

\section{Introduction}

In this article, we describe the $100 \mathrm{~K} \mathrm{X}$-ray synchrotron accurate high-resolution molecular structure and chargedensity analysis of 3(1-benzylamino-ethylidene)-chroman-2,

M. Małecka $(\bowtie) \cdot$ L. Chęcińska

Department of Structural Chemistry and Crystallography, University of Łódź, Pomorska 163/165, 90-236 Lodz, Poland e-mail: malecka@uni.lodz.pl

C. Paulmann

c/o DESY/HASYLAB, Notkestraße 85, 22603 Hamburg, Germany

C. Paulmann

Mineralogisch-Petrographisches Institut, Universität Hamburg, Grindelallee 48, 20146 Hamburg, Germany 4-dione (Mul_III) (Fig. 1) as a continuing study of the crystal structures of chromone derivatives $[1,2]$ and the recent research on the electron-density (ED) distribution in this group of compounds [3, 4].

Our interest in the chromone family is twofold. First, we aim to understand the differences between electronic properties of the molecules that confer a wide range of biological activity $[5,6]$. Second, we investigate the characters of the intramolecular and intermolecular hydrogen bonds observed in the crystal lattice.

For this reason, we present the experimental ED analysis of Mul_III as a continuation of our previous study [3] by a combined X-ray high-resolution diffraction study and highlevel density functional theoretical calculations. We focused our attention on the crystal lattice packing and the arrangement of the intra- and intermolecular hydrogen bonds. The intramolecular hydrogen bond, which could be classified as a resonance-assisted hydrogen bond (RAHB), was analyzed in detail. It is generally believed that RAHB systems are accompanied by $\pi$-electron delocalization in the $\mathrm{H}$-bonded rings (Fig. 1). Therefore, thanks to the possibility of using Bader's Quantum Theory of Atoms in Molecules (QTAIM) [7], we included detailed ED analysis to elucidate the intraand intermolecular hydrogen bonding interaction in the investigated structure. The use of QTAIM theory allowed us to conduct a more detailed examination of the nature of the weak intermolecular interaction. In addition, the focus of this study was directed to the comparison of topological parameters with previously reported aspherical models of chromone structures.

We also evaluated the properties of the source function by Gatti and Bader [8], which was recently used to characterize hydrogen bonds. It has been shown that the character of the hydrogen bond is correlated with the sign of the contribution from the hydrogen, donor, and acceptor atoms [8]. 


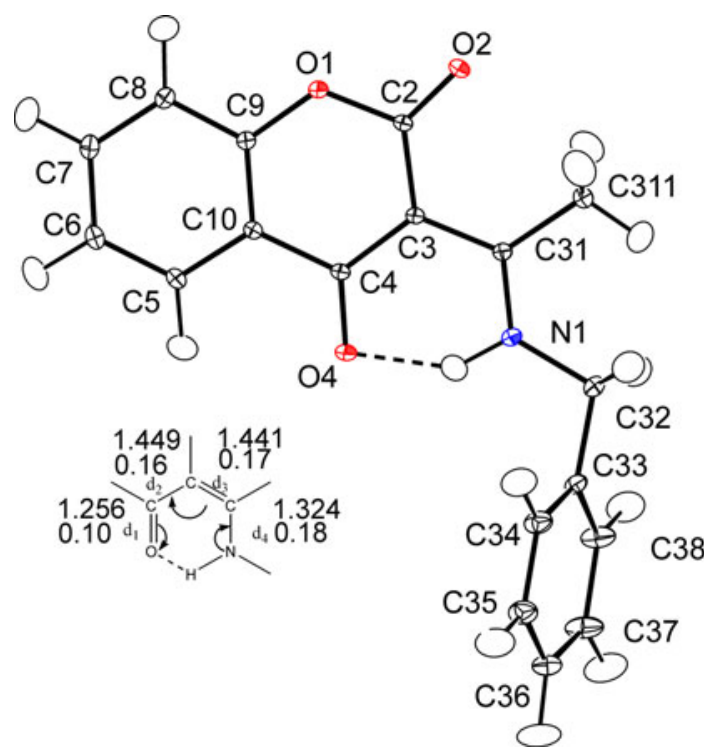

Fig. 1 ORTEP view of (III) with 50\% probability ellipsoids, showing the atomic labeling scheme. The intramolecular $\mathrm{N}-\mathrm{H} \cdots \mathrm{O}$ hydrogen bonds are displayed as dashed lines. Left RAHB system with experimental bond distances ( $\mathrm{A}$ ) (above) and corresponding experimental ellipticities (below)

In addition, the focus of this study was directed to the comparison of topological parameters with previously reported aspherical models of chromone structures. It is also worth noting that charge-density analysis is now an established subfield of crystallography and is potentially highly rewarding $[9,10]$.

\section{Experimental}

Recrystallization and data collection

Single crystals suitable for charge-density analysis were obtained by recrystallization of the samples obtained after synthesis [11]. The crystals were obtained by evaporation from toluene. Single-crystal X-ray diffraction data were collected with a $165-\mathrm{mm}$ Mar CCD detector mounted on the Huber kappa diffractometer at beamline F1 at HASYLAB/DESY. In the data collection, seven different $\varphi$ scan series at $2 \theta$ from $0^{\circ},-20^{\circ}$, and $-45^{\circ}$ with different combinations of $\omega$ and $\chi$ were performed to cover the reciprocal space. The exposure time was fixed at 5, 10, and $20 \mathrm{~s}$ for runs at $2 \theta=0^{\circ}$ and at 60,180 , and $230 \mathrm{~s}$ for high $2 \theta$ settings of $-20^{\circ}$ and $-45^{\circ}$, the scan width was $1^{\circ}$, the wavelength was $0.6 \AA$, and the sample-detector distance was $80.0 \mathrm{~mm}$. The crystal used for the experiment had dimensions of $0.1 \times 0.1 \times 0.25$. The data were collected at $100(2) \mathrm{K}$. These settings gave 93850 collected reflections up to a resolution of $\sin \theta / \lambda=1.11 \AA^{-1}$ with a completeness of $95 \%$. High-order data are needed to improve accuracy and resolution and to provide a sufficient number of data, due to increased number of variables of the Hansen-Coppens multipole model [12]. The data were integrated and scaled using the XDS software package [13].

Spherical atom refinement and multipole atom refinement

An independent data set obtained from the merging routine implemented in SHELXL97 [14] and the spherical model was entered into a multipole refinement [12].

The Hansen and Coppens multipole formalism [12] was used as implemented in the program XD [15]. The multipolar expansion of the ED distribution is expressed by

$$
\begin{aligned}
\rho_{\text {multipol }}(r)= & \rho_{\mathrm{c}}(r)+P_{\mathrm{v}} \kappa^{3} \rho_{\mathrm{v}}(\kappa r) \\
& +\sum_{l=0}^{l_{\max }} \kappa^{\prime 3} R_{l}\left(\kappa^{\prime} r\right) \sum_{m=0}^{l} P_{l m \pm} Y_{l m \pm}(\theta, \varphi)
\end{aligned}
$$

with $\rho_{\mathrm{c}}(r)$ and $\rho_{\mathrm{v}}(\kappa r)$ representing the spherical core and valence electron densities, composed of Hartree-Fock wave functions expanded by Slater-type basis functions [16] and contractible/expansible by the $\kappa$ parameter. For the deformation terms single-zeta orbitals with energyoptimized Slater exponents were taken and kept fixed. The quantity $\sum_{\mathrm{H}} w_{\mathrm{H}}\left|F_{\text {obs }}(\mathrm{H})-k F_{\text {calc }}(\mathrm{H})\right|^{2}$ was minimized using the statistical weight $w_{\mathrm{H}}=1 / \sigma^{2}\left(F_{\mathrm{obs}}(\mathrm{H})\right)$ and only those structure factors that matched the criterion of $F_{\text {obs }}^{2}(\mathrm{H})>2 \sigma\left(F_{\text {obs }}^{2}(\mathrm{H})\right)$ were included. The multipole population up to hexadecapolar level for $\mathrm{C}, \mathrm{N}$, and $\mathrm{O}$ atoms and dipoles for $\mathrm{H}$ atoms were refined using the corresponding software of the program XD [15]. During the multipole refinement, the following constraints were used: local mirror $C_{\mathrm{s}}$ symmetry was imposed on all $\mathrm{C}, \mathrm{N}$, and $\mathrm{O}$ atoms, the $\mathrm{C} 5$ atom was constrained to $\mathrm{C} 8, \mathrm{C} 6$ to $\mathrm{C} 7, \mathrm{C} 34$ to $\mathrm{C} 38$, and $\mathrm{C} 35$ to $\mathrm{C} 37$, those of $\mathrm{H} 6, \mathrm{H} 7$, and $\mathrm{H} 8$ were constrained to $\mathrm{H} 5$, those of $\mathrm{H} 35, \mathrm{H} 36, \mathrm{H} 37$, and $\mathrm{H} 38$ to $\mathrm{H} 3$, and for the $\mathrm{C} 311$ atom a local $C_{3}$ symmetry was included. $\mathrm{C}-\mathrm{H}$ and $\mathrm{N}-\mathrm{H}$ distances were fixed to neutron values [17]. The $\kappa$ parameters were refined independently for $\mathrm{C}, \mathrm{N}$, and $\mathrm{O}$ atoms and not refined for $\mathrm{H}$ atoms but kept at $\kappa=1.13$ and $\kappa^{\prime}=1.29$. In the next step, atomic displacement parameters for $\mathrm{H}$ atoms (H-ADPs) were generated by the SHADE program [18]. Finally all parameters were refined with fixed ADPs for $\mathrm{H}$ atoms. The obtained multipole model is presented here as Mul_III. The source function calculations on the experimental models were carried out using the XDPROP module of XD with the keywords SOURCE and TOPINT. For further refinement details, see also Table 1. 
Table 1 Crystal data and structure refinement for compound III at $100 \mathrm{~K}$

\begin{tabular}{|c|c|}
\hline & Compound III \\
\hline Empirical formula & $\mathrm{C}_{18} \mathrm{H}_{15} \mathrm{~N} \mathrm{O}_{3}$ \\
\hline Molecular weight & 293.31 \\
\hline Crystal description & Block, colorless \\
\hline Size (mm) & $0.25 \times 0.10 \times 0.10$ \\
\hline Crystal system & Triclinic \\
\hline Space group & $P-1$ \\
\hline$a(\AA)$ & 8.3759 (4) \\
\hline$b(\AA)$ & $9.4261(6)$ \\
\hline$c(\AA)$ & $9.8941(6)$ \\
\hline$\alpha\left({ }^{\circ}\right)$ & $81.657(5)$ \\
\hline$\beta\left({ }^{\circ}\right)$ & $85.555(7)$ \\
\hline$\gamma\left({ }^{\circ}\right)$ & $66.813(7)$ \\
\hline$V\left(\AA^{3}\right)$ & $710.28(7)$ \\
\hline$Z$ & 2 \\
\hline$d_{x}\left(\mathrm{~g} \mathrm{~cm}^{-3}\right)$ & 1.371 \\
\hline$\mu\left(\mathrm{cm}^{-1}\right)$ & 0.094 \\
\hline $\max \theta\left({ }^{\circ}\right)$ & 41.81 \\
\hline $\sin \theta / \lambda\left(\AA^{-1}\right)$ & 1.11 \\
\hline Completeness to $\sin \theta / \lambda(\%)$ & 95.3 \\
\hline No. of reflns measured & 93580 \\
\hline No. of reflns unique & $15544 R_{(\mathrm{int})}=0.0263$ \\
\hline Redundancy & 6.03 \\
\hline \multicolumn{2}{|l|}{ Spherical atom refinement } \\
\hline No. of observed reflns $(I>2 \sigma(I))$ & 13865 \\
\hline Data/restraints/parameters & $15544 / 0 / 259$ \\
\hline Goodness-of-fit on $F^{2}$ & 1.073 \\
\hline Final $R$ indices $(I>2 \sigma(I))$ & $R_{1}=0.0384 ; w R_{2}=0.1288$ \\
\hline Final $R$ indices (all data) & $R_{1}=0.0417 ; w R_{2}=0.1321$ \\
\hline \multicolumn{2}{|l|}{ Multipole atom refinement } \\
\hline No. of data & 14956 \\
\hline Data included in the refinement & 13194 \\
\hline No. of parameters & 503 \\
\hline$N_{\mathrm{ref}} / N_{\mathrm{v}}$ & 26.3 \\
\hline Final $R_{1}(F)$ & 0.0217 \\
\hline Final $R_{1 \text { all }}(F)$ & 0.0255 \\
\hline Final $w R_{2}(F)$ & 0.0260 \\
\hline Goodness-of-fit & 1.43 \\
\hline
\end{tabular}

Theoretical model

The molecular geometry from the multipole model were entered into single-point (SP) calculation were performed using density functional theory (DFT) with the B3LYP [19] functional and the standard basis set $6-311++\mathrm{G}^{* *}$ ( $S P \_$theo) in order to allow a comparison with the experimental data. In addition, optimization (OPT theo) in gas phase was also performed. The calculations were done using the program Gaussian 03 [20]. The theoretical wavefunctions obtained were evaluated with the program AIM 2000 [21] to obtain the topological parameters.

\section{Comment}

Description of structure, bond topological properties

The molecular structure from the high-resolution synchrotron data as (Mul_III) is displayed in Fig. 1. The standard low-resolution X-ray structure of presented compound was reported by us previously [22] as the independent atom model (IAM_193K).

Having the geometrical parameters for the following models: the independent atom model (IAM_193K), the multipole model ( $\left.M u l_{-} I I I\right)$, the SP calculation model (SP_theo), and the optimized model (OPT_theo), the detailed comparison was presented. In addition, the multipole model Mul_III might be compare with other experimental aspherical models of relative chromone derivatives (Mul_I, Mul_II).

There are no significant differences in the geometrical parameters of the Mul_III model in comparison with the already reported independent atom model (IAM_193K) (see Table 2). One weak $\mathrm{C}-\mathrm{H} \cdots \mathrm{O}$ interaction that has not been reported previously was found thanks to the topological analysis of the ED distribution (Table 3). In addition, the comparison of geometrical parameters between three chromone derivatives and theoretical calculated models (SP_theo, OPT_theo) does not reveal any noticeable differences.

Keeping in the mind the transferability concept of charge-density work, we also compared bond topological parameters such as the ED $\rho(r)$ and the Laplacian of ED $\nabla^{2} \rho(r)$ for three aspherical models: $M u l_{-} I I I$ and previously reported chromone derivatives (Mul_I, Mul_II) [3]. The results for the common parts of molecules - the chromone moiety and the H-bonded ring presented in Fig. 2-are in good agreement. The corresponding values of the ED $\rho(r)$ and the Laplacian of $\mathrm{ED} \nabla^{2} \rho(r)$ have been compared between aspherical models of chromone derivatives (Mul_I,Mul_II,Mul_III) and with the values obtained from the SP and optimized geometry calculation. In general, it was found that differences in the ED values $\rho(r)$ are small $\left(0.01-0.06 \mathrm{e} / \AA^{3}\right)$ for aspherical models and moderate $\left(0.1-0.2 \mathrm{e} / \AA^{3}\right)$ for aspherical/calculated models.

The Laplacians of ED $\nabla^{2} \rho(r)$ differ by a maximum of $2.0 \mathrm{e} / \AA^{5}$ and $6.5 \mathrm{e} / \AA^{3} \mathrm{c}$ when comparing aspherical models and aspherical/calculated models, respectively. For the non-polar $\mathrm{C}-\mathrm{C}$ bonds, the deviation is fair, while for the $\mathrm{C}=\mathrm{O}$ polar bonds a typical discrepancy is found between experiment and theory, which arises for well-known reasons that have been summarized recently [23]. As has been 
Table 2 Bond distances $(\AA)$ in the main fragment of chromone derivatives

\begin{tabular}{|c|c|c|c|c|c|c|}
\hline & IAM_193K & Mul_III & $S P \_$theo & OPT_theo & Mul_I & Mul_II \\
\hline $\mathrm{O} 1-\mathrm{C} 2$ & $1.3894(18)$ & $1.3898(3)$ & 1.3898 & 1.3935 & $1.3821(3)$ & $1.3906(3)$ \\
\hline $\mathrm{O} 1-\mathrm{C} 9$ & $1.3727(17)$ & $1.3701(3)$ & 1.3701 & 1.3636 & 1.3791(3) & $1.3744(3)$ \\
\hline $\mathrm{O} 2-\mathrm{C} 2$ & $1.2092(18)$ & $1.2192(3)$ & 1.2192 & 1.2098 & $1.2272(3)$ & $1.2165(3)$ \\
\hline O4-C4 & $1.2534(18)$ & $1.2562(2)$ & 1.2562 & 1.2482 & $1.2562(4)$ & $1.2569(3)$ \\
\hline N1-C31 & $1.3171(18)$ & $1.3235(3)$ & 1.3235 & 1.3291 & $1.3216(4)$ & $1.3258(2)$ \\
\hline $\mathrm{C} 2-\mathrm{C} 3$ & $1.4471(19)$ & $1.4520(2)$ & 1.4520 & 1.4590 & $1.4524(4)$ & $1.4616(2)$ \\
\hline C3-C4 & $1.4391(18)$ & $1.4487(3)$ & 1.4487 & 1.4538 & $1.4526(3)$ & $1.4469(3)$ \\
\hline C3-C31 & $1.4389(19)$ & $1.4412(3)$ & 1.4412 & 1.4275 & $1.4327(3)$ & $1.4301(2)$ \\
\hline C4-C10 & $1.4733(18)$ & $1.4760(3)$ & 1.4760 & 1.4728 & $1.4778(3)$ & $1.4713(3)$ \\
\hline C5-C6 & $1.3800(18)$ & $1.3914(3)$ & 1.3914 & 1.3852 & $1.3932(3)$ & $1.3905(3)$ \\
\hline C5-C10 & $1.3980(18)$ & $1.4082(3)$ & 1.4082 & 1.4031 & $1.4078(4)$ & $1.4090(2)$ \\
\hline C6-C7 & $1.3910(18)$ & $1.4072(3)$ & 1.4072 & 1.4019 & $1.4084(3)$ & $1.4065(3)$ \\
\hline $\mathrm{C} 7-\mathrm{C} 8$ & $1.3800(18)$ & $1.3938(3)$ & 1.3938 & 1.3875 & $1.3965(3)$ & $1.3955(3)$ \\
\hline C8-C9 & $1.3920(18)$ & 1.3991(3) & 1.3991 & 1.3964 & $1.4015(4)$ & $1.3995(3)$ \\
\hline C9-C10 & $1.3850(18)$ & $1.3954(3)$ & 1.3954 & 1.3944 & $1.3978(4)$ & $1.3963(2)$ \\
\hline
\end{tabular}

The following models are compared: $I A M \_193 \mathrm{~K}$ an independent atom model structure measured at $193 \mathrm{~K}$ (standard SHELX refinement) [22], Mul_III aspherical ED model at $100 \mathrm{~K}, S P \_$theo SP computed model, OPT_theo model with optimized geometry at B3LYP/6-311++G** level, Mul_I and Mul_II aspherical atom models at $100 \mathrm{~K}$ for related compounds (I) and (II), respectively [3]

Table 3 Geometrical (in $\AA{ }^{\circ}$ ) topological parameters ( $\rho$ in e/ $/ \AA^{3}, \nabla^{2} \rho$ in $\mathrm{e} / \AA^{5}$ ), hydrogen bonding energies (in kJ/mol), and local energy densities (in $\mathrm{kJ} / \mathrm{mol}$ per atomic unit volume) for intra- and intermolecular hydrogen bonds

\begin{tabular}{llllllllllll}
\hline & $\mathrm{D}-\mathrm{H}$ & $\mathrm{H} \cdots \mathrm{A}$ & $\mathrm{D} \cdots \mathrm{A}$ & $<\mathrm{D}-\mathrm{H} \cdots \mathrm{A}$ & $\rho$ & $\nabla^{2} \rho$ & $\mathrm{E}_{\mathrm{HBgeom}}$ & $\mathrm{E}_{\mathrm{HB}}$ & $G$ & $V$ \\
\hline Compound III & & & & & & & & & & & \\
$\mathrm{N} 1-\mathrm{H} 1 \cdots \mathrm{O} 4$ & 1.01 & 1.67 & $2.556(1)$ & 144 & $0.36(1)$ & $4.7(1)$ & -61.96 & -77.93 & 141.52 & -155.85 & -14.33 \\
& 1.01 & 1.67 & 2.560 & 144 & 0.35 & 3.9 & -61.02 & -69.21 & 122.54 & -138.41 & -15.87 \\
& 1.03 & 1.68 & 2.564 & 141 & 0.35 & 3.8 & -61.12 & -67.61 & 119.46 & -135.23 & -15.77 \\
$\mathrm{C} 6-\mathrm{H} 6 \cdots \mathrm{O} 2^{\mathrm{i}}$ & 1.08 & 2.28 & $3.304(1)$ & 157 & $0.07(1)$ & $1.2(1)$ & -6.89 & -9.00 & 24.84 & -18.00 & 6.84 \\
$\mathrm{C} 311-\mathrm{H} 31 \mathrm{C} \cdots \mathrm{O} 2^{\mathrm{ii}}$ & 1.06 & 2.46 & $3.438(1)$ & 154 & $0.04(1)$ & $0.7(1)$ & -3.61 & -4.89 & 14.62 & -9.78 & 4.83 \\
$\mathrm{C} 38-\mathrm{H} 38 \cdots \mathrm{O} 2^{\text {iii }}$ & 1.08 & 2.54 & $3.436(1)$ & 139 & $0.04(1)$ & $0.6(1)$ & -2.70 & -4.27 & 12.70 & -8.55 & 4.16 \\
$\mathrm{C} 36-\mathrm{H} 36 \cdots \mathrm{O} 4{ }^{\text {iv }}$ & 1.08 & 2.47 & $3.413(1)$ & 145 & $0.05(1)$ & $0.7(1)$ & -3.48 & -5.08 & 14.98 & -10.16 & 4.82 \\
\hline
\end{tabular}

$E_{\mathrm{HBgeom}}$ calculated according to Espinosa [23] $\left(\mathrm{E}=25.3 \times 10^{3} \mathrm{e}^{-3.6(\mathrm{H} \cdots \mathrm{A})}\right)$ and $E_{\mathrm{HB}}=\frac{1}{2} V\left(r_{\mathrm{BCP}}\right)$. For the intramolecular $\mathrm{N} 1-\mathrm{H} 1 \cdots \mathrm{O} 4 \mathrm{hydrogen}$ bond the first line refers to the Mul_III model, the second to SP_theo, and the third to OPT_theo

Symmetry code: (i) $x, 1+y, z$; (ii) $-x,-y, 2-z$, (iii) $1-x,-y, 2-z$; (iv) $1-x, 1-y, 1-z$

shown above, the density and derived properties of submolecular fragments of three compounds possess a high degree of transferability, which is the key concept in Bader's theory of "Atoms in Molecules" [7].

\section{Geometry of the RAHB and topological parameters}

On the basis of the geometrical and topological parameters we focused on the intramolecular $\mathrm{H}$-bond and classified it as the RAHB. In 1989, Gilli [24] introduced the RAHB model with the strengthening of the $\mathrm{O} / \mathrm{N}-\mathrm{H} \cdots \mathrm{O}$ hydrogen bonds as a consequence of the $\pi$-delocalization (Fig. 1) within the $\mathrm{O}=\mathrm{C}-\mathrm{C}=\mathrm{C}-\mathrm{O} / \mathrm{N}-\mathrm{H}$ of the keto-enol or ketoamine fragment [25]. As discussed by Bader and coworkers
$[26,27]$, the preferential accumulation of charge due to $\pi$-bonding in organic molecules is most apparent by examination of the bond ellipticity. With respect to our previous results it is not surprising to find higher ellipticity values for bonds $d_{1}, d_{2}, d_{3}$, and $d_{4}$ in the $\mathrm{O}=\mathrm{C}-\mathrm{C}=\mathrm{C}-\mathrm{N}-\mathrm{H}$ fragment as well as the shortening and lengthening of $d_{2}$ and $d_{3}$ compared with the reference values [28, 29] (see Fig. 1). The ED values of the $\mathrm{C} 3-\mathrm{C} 4$ and $\mathrm{C} 3-\mathrm{C} 31$ bonds, $\rho(r)=1.79$ and $1.82 \mathrm{e} / \AA^{3}$, respectively, are nearly equal, and they are higher than the value for the formally single bond (C31-C311), $\rho(r)=1.63 \mathrm{e} / \AA^{3}$. This tendency was in our previous studies [3] and indicates a $\pi$-electron delocalization within a hydrogen bonded ring containing a conjugated system of single and double bonds. 

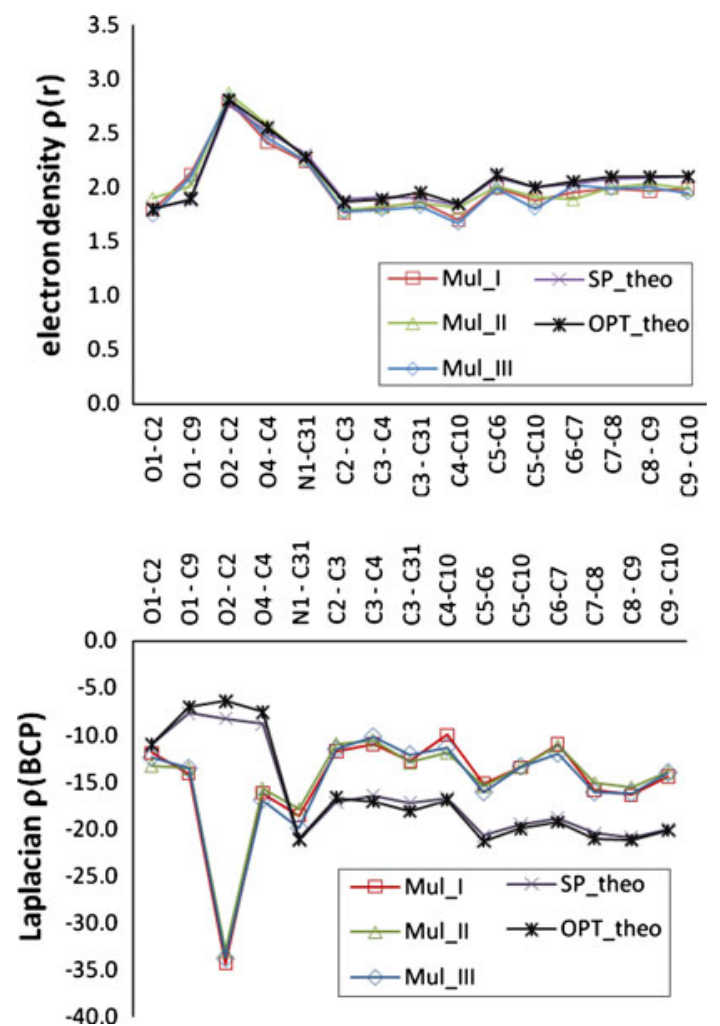

Fig. 2 Comparison of the $\rho(r)$ and Laplacians of the electron densities $\nabla^{2} \rho(r)\left(\rho(r)\right.$ in e/ $/ \AA^{3}, \nabla^{2} \rho(r)$ in e/ $\left.\AA^{5}\right)$ for selected bonds in the main/common part of chromone derivatives. Mul_I and Mul_II refer to previously reported charge-density studies of chromone derivatives [3], Mul_III refers to aspherical atom model, SP_theo and $O P T_{-}$theo refer to the model obtained by theoretical calculation (SP) and optimized geometry, respectively

The last method used to characterize the RAHB is a Green's function, which is also called the source function (S) [8]. The source function was recently developed by Gatti and Bader [8] and successfully supported other investigations $[30,31]$.

The source function divides the ED at a point in space, for example, a bond critical point (BCP), into atomic contributions of the hydrogen atom. For RAHBs, the source contribution from hydrogen appears positive but close to zero. It is slightly negative for polarized-assisted hydrogen bonds, highly negative for isolated hydrogen bonds, and largely positive for charge assisted hydrogen bonds [32]. Calculation of the source function of the structure further confirmed that the $\mathrm{N}-\mathrm{H} \cdots \mathrm{O}$ hydrogen bond can be classified as RAHB. RAHBs have a very small positive source from the hydrogen atom, $S(\mathrm{H})$, and a similar source contribution from donor and acceptor atoms, $S(\mathrm{D})$ and $S(\mathrm{~A})$. The contributions from the $\mathrm{H}, \mathrm{D}$, and $\mathrm{A}$ atoms are 3.7, 24.1, and $22.3 \%$ for $S(\mathrm{H}), S(\mathrm{D})$, and $S(\mathrm{~A}) \%$, respectively. Figure 3 presents the contribution of $\mathrm{H}$, D-donor, and A-acceptor atoms at BCP for the $\mathrm{N} 1-\mathrm{H} 1 \cdots \mathrm{O} 4$ hydrogen bond in comparison to our previous study. This

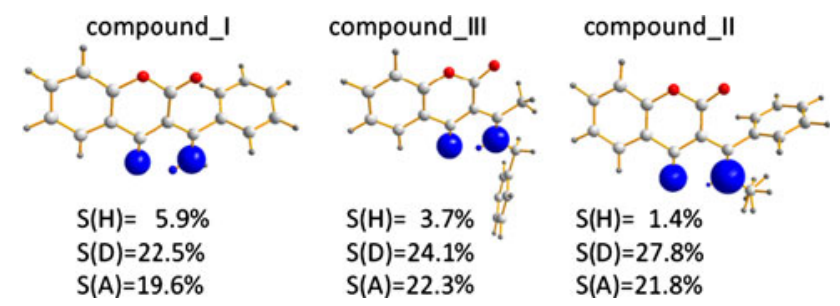

Fig. 3 Percentage atomic source contributions to the ED at the BCP

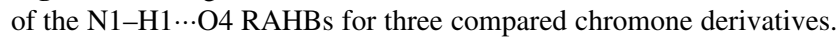
Contributions are displayed as circles whose sizes are proportional to the percentage contribution from each $\mathrm{H}, \mathrm{N}$ (donor), $\mathrm{O}$ (acceptor) atoms involved in the hydrogen bond. Blue color represents a positive contribution of the source function. For presented compound (III) and related derivatives (I, II) the small positive source contribution from hydrogen indicates $\mathrm{N}-\mathrm{H} \cdots \mathrm{O}$ hydrogen bond as RAHB (Color figure online)

correlates well with the results from our latest investigations [3].

Intermolecular hydrogen bonds

The crystal packing of the structure Mul_III reveals the existence of four intermolecular $\mathrm{C}-\mathrm{H} \cdots \mathrm{O}$ contacts with $\mathrm{H} \cdots \mathrm{O}$ distances below $2.6 \AA$ (see Table 3), one more than in the IAM_193K structure [22]. The shortest intermolecular interaction is $\mathrm{H} 6 \cdots \mathrm{O} 2^{\mathrm{i}}=2.28 \AA$ (symmetry code (i): $x, 1+y, z$ ).

In this article, our investigations are augmented by detailed analysis of topological parameters using QTAIM. BCPs are found for all four contacts. Therefore, the electron properties at BCPs allow the energetic properties to be calculated using the following Abramov [33] expressions:

$$
\begin{aligned}
G\left(r_{\mathrm{BCP}}\right) & =\frac{3}{10}\left(3 \pi^{2}\right)^{\frac{2}{3}} \rho^{\frac{5}{3}}\left(r_{\mathrm{BCP}}\right)+\frac{1}{6} \nabla^{2} \rho\left(r_{\mathrm{BCP}}\right) \\
V\left(r_{\mathrm{BCP}}\right) & =\frac{1}{4} \nabla^{2}\left(r_{\mathrm{BCP}}\right)-2 G\left(r_{\mathrm{BCP}}\right)
\end{aligned}
$$

Together with the geometrical parameters and hydrogen bond energy calculated by the distance dependent relation $E=25.3 \times 10^{3} \mathrm{e}^{-3.6(\mathrm{H} \cdots \mathrm{A})}$ [34] or estimated energy following the Espinosa equation $E_{\mathrm{HB}}=\frac{1}{2} V\left(r_{\mathrm{BCP}}\right)[34,35]$ and the total electron energy density $H\left(r_{\mathrm{BCP}}\right)=G\left(r_{\mathrm{BCP}}\right)+$ $V\left(r_{\mathrm{BCP}}\right)$ [35], these parameters provide good descriptors for the determination of the nature of the hydrogen bond (Table 3). Taking into account $H\left(r_{\mathrm{BCP}}\right)$ and $\nabla^{2} \rho\left(r_{\mathrm{BCP}}\right)$ together we can classify the character of the hydrogen bond interactions [36]:

- Strong H-bonds of covalent character $\left(\nabla^{2} \rho\left(r_{\mathrm{BCP}}\right)<0\right.$ and $\left.H\left(r_{\mathrm{BCP}}\right)<0\right)$,

- Medium strength H-bonds of partially covalent character $\left(\nabla^{2} \rho\left(r_{\mathrm{BCP}}\right)>0\right.$ and $\left.H\left(r_{\mathrm{BCP}}\right)<0\right)$, and

- Weak H-bonds of mainly electrostatic character $\left(\nabla^{2} \rho\left(r_{\mathrm{BCP}}\right)>0\right.$ and $\left.H\left(r_{\mathrm{BCP}}\right)>0\right)$. 
Herein all $\mathrm{C}-\mathrm{H}$-..O hydrogen bonds are weak, having an electrostatic character according to the Rozas approach

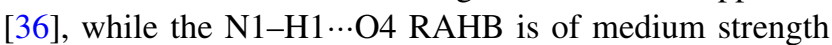
with partially covalent character. In addition, there is good agreement between the theoretically calculated and experimentally obtained values.

\section{Conclusion}

The aspherical model of presented chromone derivative obtained using the data set collected with synchrotron radiation at $100 \mathrm{~K}$ afforded good agreement with our previous charge-density work and high-level DFT calculations. All expected intramolecular and intermolecular BCPs were identified and analyzed using QTAIM methods. It is shown that the topological properties of the hydrogen bonds indicate the covalent nature of the $\mathrm{N}-\mathrm{H} \cdots \mathrm{O}$ medium strength intramolecular hydrogen bond and weak $\mathrm{C}-\mathrm{H} \cdots \mathrm{O}$ intermolecular hydrogen bonds with electrostatic nature. A comparison of the ED $\rho(r)$ and ellipticity shows $\pi$-delocalization within the $\mathrm{H}$-bonded ring. The source function was introduced to analyze the intramolecular hydrogen bond and confirmed that the $\mathrm{N}-\mathrm{H} \cdots \mathrm{O}$ hydrogen bond can be considered as the RAHB. This finding is in accordance with the previous results for chromone derivatives.

\section{Supplementary data}

CCDC 829929 contains the supplementary crystallographic data for the multipole refinement for this article. These data can be obtained free of charge at www.ccdc.cam.ac.uk/ conts/retrieving.html (or from the Cambridge Crystallographic Data Centre (CCDC), 12 Union Road, Cambridge, CB2 1EZ, UK; fax: +44 (0) 1223-336033; email: deposit@ccdc.cam.ac.uk).

Acknowledgments The research leading to these results has received funding from the European Community's Seventh Framework Programme (FP7/2007-2013) under Grant Agreement No. 226716. The high-resolution measurements were carried out within the project I-20090042 EC at the light source DORIS III at HASYLAB/DESY, Hamburg, Germany. Theoretical calculations were carried out at the Cracow Supercomputing Centre (Poland). The authors thank the University of Łódź for financial support (University Research Grants: Grant No. 505/721/R 2010).

\section{References}

1. Małecka M, Grabowski SJ, Budzisz E (2004) Chem Phys 297:235-244

2. Małecka M, Ciołkowski M, Budzisz E (2010) Acta Crystallogr E66:0246
3. Małecka M, Chęcińska L, Rybarczyk-Pirek A, Morgenroth W, Paulmann C (2010) Acta Crystallogr B66:687-695

4. Małecka M (2007) J Mol Struct 831:135-143

5. Khan KM, Ambreen N, Hussain S, Perveen S, Choudhary MI (2009) Bioorg Med Chem 17:2983-2988

6. Grażul M, Budzisz E (2009) Coord Chem Rev 253:2588-2598

7. Bader RFW (1990) Atoms in molecules-a quantum theory. Oxford University Press, New York

8. Gatti C, Bader RFW (1998) Chem Phys Lett 287:233-238

9. Overgaard J, Hibbs DE (2004) Acta Crystallogr A60:480-487

10. Luger P (2007) Org Biomol Chem 5:2529-2540

11. Budzisz E, Brzezinska E, Krajewska U, Rozalski M (2003) Eur J Med Chem 38:597-603

12. Hansen NK, Coppens P (1978) Acta Crystallogr A34:909-921

13. Kabsch W (1993) J Appl Crystallogr 26:795-800

14. Sheldrick GM (2008) Acta Crystallogr A64:112-122

15. Volkov A, Macchi P, Farrugia LJ, Gatti C, Mallinson P, Richter T, Koritsanszky T (2006) XD2006-a computer program package for multipole refinement, topological analysis of charge densities and evaluation of intermolecular energies from experimental or theoretical structure factors. Program Version 5.33

16. Clementi E, Roetti C (1974) At Data Nucl Data Tables 14:177

17. Allen FH, Kennard O, Watson DG, Brammer L, Orpen AG, Taylor R (1992) International tables for X-ray crystallography. Kluwer Academic Publishers, Amsterdam

18. Madsen AØ (2006) J Appl Crystallogr 39:757-758

19. Becke AD (1993) J Chem Phys 98:5648-5652

20. Frisch MJ, Trucks GW, Schlegel HB, Scuseria GE, Robb MA, Cheeseman JR, Montgomery JA Jr, Vreven T, Kudin KN, Burant JC, Millam JM, Iyengar SS, Tomasi J, Barone V, Mennucci B, Cossi M, Scalmani G, Rega N, Petersson GA, Nakatsuji H, Hada M, Ehara M, Toyota K, Fukuda R, Hasegawa J, Ishida M, Nakajima T, Honda Y, Kitao O, Nakai H, Klene M, Li X, Knox JE, Hratchian HP, Cross JB, Adao C, Jaramill J, Gomperts R, Stratmann RE, Yazyev O, Austin AJ, Cammi R, Pomelli C, Ochterski JW, Ayala PY, Morokuma K, Voth GA, Salvador P, Dannenberg JJ, Zakrzewski VG, Dapprich S, Daniels AD, Strain MC, Farkas O, Malick DK, Rabuck AD, Raghavachari K, Foresman JB, Ortiz JV, Cui Q, Baboul AG, Clifford S, Cioslowski J, Stefanov BB, Liu G, Liashenko A, Piskorz P, Komaromi I, Martin RL, Fox DJ, Keith T, Al-Laham MA, Peng CY, Nanayakkara A, Challacombe M, Gill PMW, Johnson B, Chen W, Wong MW, Gonzalez C, Pople JA (2003) Gaussian 03. Gaussian, Inc., Pittsburgh

21. Biegler-König F, Schonbohm J (2002) J Comp Chem 23: 1489-1494

22. Małecka M, Budzisz E (2006) Acta Crystallogr E62:0505805060

23. Koritsanszky TS (2006) In: Grabowski SJ (ed) Hydrogen bonding-new insights. Springer, Dordrecht

24. Gilli P, Bellucci F, Ferretti V, Bertolasi VG (1989) J Am Chem Soc 111:1023-1028

25. Sobczyk L, Grabowski SJ, Krygowski TM (2005) Chem Rev 105:3513-3560

26. Bader RFW, Slee TS, Cremer D, Kraka E (1983) J Am Chem Soc 105:5061-5068

27. Cremer D, Kraka E, Slee TS, Bader RFW, Lau CDH, NguyenDang TT, MacDougall P (1983) J Am Chem Soc 105:5069-5076

28. Popelier P (2000) Atoms in molecules: an introduction. Pearson Education Limited, Harlow

29. Allen FH, Kennard O, Watson DG, Brammer L, Orpen AG, Taylor R (1987) Chem Soc Perkin Trans 2:S1-S83

30. Overgaard J, Schiøtt B, Larsen FK, Iversen BB (2001) Chem Eur J 7:3756-3767

31. Gatti C, Bertini L (2004) Acta Crystallogr A60:438-449 
32. Gatti C, Cargnoni F, Bertini L (2003) J Comput Chem 24: $422-436$

33. Abramov YA (1997) Acta Crystallogr A53:264-272

34. Espinosa E, Molins E, Lecomte C (1998) Chem Phys Lett 285: $170-173$
35. Espinosa E, Alkorta I, Elguero J, Molins E (2002) J Chem Phys 117:5529-5542

36. Rozas I, Alkorta I, Elguero J (2000) J Am Chem Soc 122: 11154-11161 